\title{
Distal radial artery cannulation in the anatomical snuffbox is useful for arterial blood pressure monitoring in neurosurgery: a case report
}

\author{
Ryusuke Tanaka* (D, Tohru Shiratori, Chiaki Kiuchi and Junichi Sasao
}

To the Editor:

Conventional radial artery (RA) cannulation at the wrist interferes with electrode placement for intraoperative neurophysiological monitoring (IONM) and is often troubled by dampened arterial waveforms after postural changes. We report the use of distal radial artery (DRA) cannulation in the anatomical snuffbox for arterial blood pressure $(\mathrm{ABP})$ monitoring during a spine surgery requiring IONM and postural changes.

An 89-year-old man underwent extreme lateral interbody fusion in the right lateral decubitus and prone positions with motor evoked potential (MEP) monitoring. After inducing anesthesia with propofol and remifentanil, his wrist was adducted on a roll with the point of cannulation facing upwards. We successfully inserted a 22-gauge cannula (Surflo; TERUMO, Tokyo, Japan) in the DRA in the anatomical snuffbox on the first attempt under ultrasound guidance (Fig. 1a). This technique of DRA cannulation provided good ABP monitoring throughout surgery.

In recent times, the DRA has been increasingly cannulated for cardiac and neurosurgical interventions $[1,2]$. Based on our experience, the advantages of using the DRA for ABP monitoring in neurosurgery are as follows: (1) the stimulating electrodes for the assessment of somatosensory evoked potentials and the recording electrodes for MEP are placed above the median nerve at the wrist and the abductor pollicis brevis, respectively. Thus, RA cannulation at the wrist interferes with the proper placement of these electrodes. DRA cannulation avoids this interference and enables the adequate stimulation and recording that is necessary for reliable IONM. (2) The arterial waveform is stable in the prone and lateral decubitus positions because DRA cannulation in the anatomical snuffbox permits pronation of the patient's forearm. In the prone and lateral decubitus positions, the palmar aspects of the pronated arms face the padded armrests. This frequently dampens the arterial waveform monitored by the conventional RA cannulation method. Additionally, the arterial wave forms obtained by cannulation of the DRA are less affected by wrist flexion during postural changes than those obtained by conventional RA cannulation [3].

The DRA is distal to the division of the superficial palmar branch of the RA (Fig. 1b). It continues as the deep palmar arch and receives collateral flow from the superficial palmar branch and the ulnar artery [2, 4]. Therefore, DRA cannulation confers lesser risk of ischemia compared to the conventional technique of RA cannulation [2, 4]. It has also been reported that the occurrence of other complications, including hematomas and neuropathy, did not significantly differ between these two approaches [1, 3]. However, the possibility of nerve injury should be considered because the superficial branch of the radial nerve is near the entry point of DRA cannulation [3]. Further well-designed studies are needed for ensuring the safety of DRA cannulation during the perioperative period. In addition, the DRA may be more difficult to

\footnotetext{
* Correspondence: rtanaka@shinshu-u.ac.jp

Division of Anesthesiology, Ina Central Hospital, 1313-1 Koshiroukubo, Ina City, Nagano 396-8555, Japan
}

\section{Springer Open}

(c) The Author(s). 2020 Open Access This article is licensed under a Creative Commons Attribution 4.0 International License, which permits use, sharing, adaptation, distribution and reproduction in any medium or format, as long as you give appropriate credit to the original author(s) and the source, provide a link to the Creative Commons licence, and indicate if changes were made. The images or other third party material in this article are included in the article's Creative Commons licence, unless indicated otherwise in a credit line to the material. If material is not included in the article's Creative Commons licence and your intended use is not permitted by statutory regulation or exceeds the permitted use, you will need to obtain permission directly from the copyright holder. To view a copy of this licence, visit http://creativecommons.org/licenses/by/4.0/. 

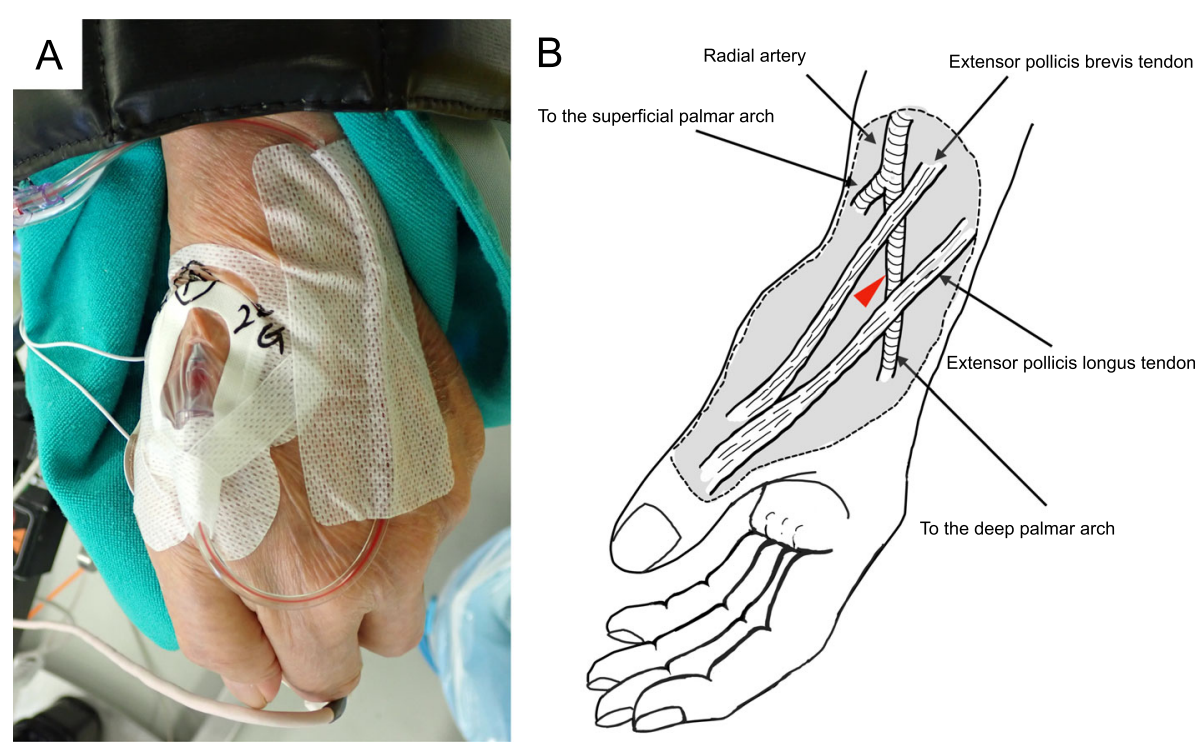

Fig. 1 a Distal radial artery cannulation in the anatomical snuffbox. An electrode for recording the motor evoked potential from the abductor pollicis brevis is attached to the thenar area. The left forearm is pronated and fixed on a padded armrest in the right lateral decubitus position. $\mathbf{b}$ Anatomical scheme of the entry point for cannulation of the dorsal radial artery of the left hand. The entry point is indicated by the red arrowhead

cannulate than the RA due to its smaller diameter [1], which is a limitation of DRA cannulation.

In conclusion, the DRA in the anatomical snuffbox can be a useful site for ABP monitoring in neurosurgery and enables adequate electrode positioning for neurophysiological assessments.

\section{Abbreviations}

ABP: Arterial blood pressure; DRA: Distal radial artery; IONM: Intraoperative neurophysiological monitoring; MEP: Motor evoked potential; RA: Radial artery

\section{Acknowledgements}

The authors would like to thank Kengo Fujita M.D. (Ina Central Hospital, Ina City, Nagano, Japan) for illustrating Fig 1 b.

\section{Authors' contributions}

RT and TS participated in the anesthetic management and drafted the manuscript. CK and JS revised the manuscript. All authors have read and approved the final manuscript.

\section{Funding}

Not applicable

\section{Availability of data and materials}

Not applicable

\section{Ethics approval and consent to participate}

Not applicable

\section{Consent for publication}

Written informed consent was obtained from the patient for the publication of this report and accompanying images.

\section{Competing interests}

The authors declare that they have no competing of interests.
Received: 7 July 2020 Accepted: 21 July 2020

Published online: 01 August 2020

\section{References}

1. Coomes EA, Haghbayan H, Cheema AN. Distal transradial access for cardiac catheterization: a systematic scoping review. Catheter Cardiovasc Interv. 2019. https://doi.org/10.1002/ccd.28623 [Epub ahead of print].

2. McCarthy DJ, Chen SH, Brunet MC, Shah S, Peterson E, Starke RM. Distal radial artery access in the anatomical snuffbox for neurointerventions: Case Report. World Neurosurg. 2019;122:355-9.

3. Kimura Y, Kimura S, Inoue H, Yamauchi M, Sumita S. Comparison of usefulness of the dorsal branch of the radial artery with the radial artery for arterial cannulation (in Japanese with English abstract). Masui. 2012;61:728-32.

4. Deepika K, Palaniappan D, Fuhrman T, Saltzmanm B. Anatomic snuffbox radial artery cannulation. Anesth Analg. 2010;111:1078-9.

\section{Publisher's Note}

Springer Nature remains neutral with regard to jurisdictional claims in published maps and institutional affiliations.

\section{Submit your manuscript to a SpringerOpen ${ }^{\mathcal{O}}$ journal and benefit from:}

- Convenient online submission

- Rigorous peer review

- Open access: articles freely available online

- High visibility within the field

- Retaining the copyright to your article

Submit your next manuscript at $\boldsymbol{\nabla}$ springeropen.com 